Article

\title{
Optimal Channel Structure for Remanufacturing under Cap-and-Trade Regulation
}

\author{
Ying Teng ${ }^{1}\left(\mathbb{D}\right.$ and Binggang Feng ${ }^{2, *}$ \\ 1 School of Management and Economic, University of Electronic Science and Technology of China, \\ Chengdu 611731, China; tengy@uestc.edu.cn \\ 2 Chengdu Institute for High-Quality Development, Chengdu 610041, China \\ * Correspondence: fengbgcd@gmail.com
}

Citation: Teng, Y.; Feng, B. Optimal Channel Structure for Remanufacturing under Cap-and-Trade Regulation. Processes 2021, 9, 370. https://doi.org/ $10.3390 /$ pr 9020370

Academic Editor: Chih-Te Yang

Received: 14 January 2021

Accepted: 15 February 2021

Published: 17 February 2021

Publisher's Note: MDPI stays neutral with regard to jurisdictional claims in published maps and institutional affiliations.

Copyright: (c) 2021 by the authors. Licensee MDPI, Basel, Switzerland. This article is an open access article distributed under the terms and conditions of the Creative Commons Attribution (CC BY) license (https:// creativecommons.org/licenses/by/ $4.0 /)$.

\begin{abstract}
In recent years, carbon cap-and-trade has been promoted by many national governments aiming to limit, or cap, total carbon dioxide emissions. Such a mechanism impacts manufacturers' remanufacturing decisions, as it increases the cost of carbon emissions. The current literature has recognized the importance of carbon cap-and-trade regulations; however, little attention has been paid to what effect such regulations have on manufacturer's remanufacturing with the flexibility to engage it in-house or outsource it to third-party remanufacturers. To fill this gap, we develop two theoretical models that, under the carbon cap-and-trade mechanism, allow the manufacturer to engage in remanufacturing operations in-house (Model $\mathrm{H}$ ) or outsource them to an independent remanufacturer (Model R). The primary goal of this paper is to understand what effects carbon cap-and-trade regulations have on green supply chain management when producing new and remanufactured products. In particular, we find that although the manufacturer has a higher incentive to reduce the carbon emissions per remanufactured unit in Model $\mathrm{H}$, the total carbon emissions may be higher than the value in Model $\mathrm{R}$, because the sales volume effect dominates in that case. As such, our analysis suggests that environmental groups and agencies should not only take effective measures to stimulate the incentive of reducing the carbon emissions per unit but must also take care regarding the supply chain structure to limit the volume effect.
\end{abstract}

Keywords: sustainable supply chain; carbon cap-and-trade; remanufacturing outsourcing; sustainability; game theory

\section{Introduction}

The negative impact of warming in the climate system is undeniable due to its impact on the widespread melting of snow and ice, rising global average sea level, and problems associated with human health. This increase in average global temperatures is largely driven by an increase in emissions from greenhouse gases, such as carbon dioxide [1]. Such a tendency has been particularly notable in recent decades. For example, in 1750, the concentration of carbon dioxide in the atmosphere was approximately 277 parts per million (ppm) [2], while this number had increased to 407 ppm in 2018 [3]. Fortunately, the problems relating to carbon emissions have recently received much attention in many countries. For example, in 18 March 2015, seeking to spur other nations to get serious about climate change, President Obama ordered the federal government to cut its greenhouse gas emissions by as much as $28 \%$ over the following decade [4]. Similarly, the European Union (EU) announced its commitment to cut carbon emissions by at least $40 \%$ by 2030 [5].

In recent years, carbon cap-and-trade has been a concept promoted by many national governments aiming to limit, or cap, the total carbon dioxide emissions. In practice, carbon cap-and-trade regulation, as a market-based mechanism, has been proposed by green supply chain management to mitigate carbon emissions: under the carbon cap-and-trade regulation, a threshold limit or carbon emission cap for a firm is set, and if a firm's carbon emissions exceed this threshold, it should purchase extra carbon emissions permits from a 
carbon market; otherwise, it can sell the surplus carbon emissions permits. In response, the USA launched a business system of trading emissions called the Chicago Climate Exchange in 2000. Subsequently, the EU launched the European Climate Exchange for trading carbon emissions in Europe and internationally in 2005. In fact, such carbon trading market operations can be observed in many countries, such as Australia, Japan, China, etc.

The carbon cap-and-trade mechanism can have a significant impact on operations management due to the potential costs or benefits associated with carbon emissions [6]. For example, in 2005, the average prices for carbon emissions stabilized at around 22 Euro per ton of carbon dioxide, with a peak of 29.15 Euro in the middle of July 2005 [7]. Such variety in the emission trading price not only directly impacts the firms' profits but also indirectly affects their production decisions. To reduce the carbon emissions and meet the regulations issued by the U.S. Environmental Protection Agency, Xerox, which is in the top 50 of the world's largest companies working on environmental sustainability, has heavily invested in environmental technology, and it reduced its production of carbon emissions by $94 \%$ between 1991 and 2006 [8]. Meanwhile, to reduce the carbon emissions in production and advance the brand image, Gree, which is a leading firm in electric appliances in China's market, has invested more than 5 billion RMB in environmental technology research and development so as to improve the energy efficiency ratio of its products, such as air conditioners, home appliances, high-end equipment, and communication equipment [9]. In China's market, the average cost of using the reducing carbon emission facilities is about CNY 180 [10]. Apparently, carbon cap-and-trade is a burden for manufacturers' production decisions, as it increases the cost of production regarding carbon emissions [6].

It should be noted that remanufacturing is often considered green supply chain management working toward sustainability because, compared with manufacturing, such closed-loop control can reduce production costs and carbon emissions [7,11,12]. For example, in terms of the economic performance, the U.S. remanufacturing industry grew by $15 \%$ to at least $\$ 43$ billion and reduced carbon dioxide emissions by $53 \%$ annually between 2009 and 2011 [13]. Similarly, the European Commission estimated that changing the linear extract-produce-use-dump material flow model into the circular economy-type economic model can create $€ 600$ billion gains per year for the EU alone [14]. Considering the potential benefits created by remanufacturing, some manufacturers, even those unable to set up low-cost remanufacturing by themselves, have chosen to outsource their remanufacturing operations to independent remanufacturers [15]. According to a survey of the U.S. remanufacturing industry, third-party remanufacturers accounted for $96 \%$ of more than 2000 remanufacturing firms [16]. Apparently, irrespective of whether remanufacturing operations are undertaken by manufacturers or third-party remanufacturers, carbon cap-and-trade influences the closed-loop control decisions in terms of both the economic performance and environmental sustainability.

The primary goal of this paper is to understand what effects carbon cap-and-trade regulations have on green supply chain management when producing new and remanufactured products. More specifically, in this paper, we develop two theoretical models that, under the carbon cap-and-trade mechanism, allow the manufacturer to engage in remanufacturing operations in-house (Model $\mathrm{H}$ ) or outsource them to an independent remanufacturer (Model R). These two theoretical models may be consistent with the U.S. remanufacturing industry. For example, some brand name original equipment manufacturers (OEMs), including HP, Xerox, General Electric Company, and Ford, have undertaken their remanufacturing operations in-house. However, other OEMs, such as IBM, Apple, Cummins, and Land Rover, have outsourced their remanufacturing operations to independent remanufacturers. Using these two models, we intend to address several new and critical questions, as follows:

- How do the carbon cap-and-trade regulations impact the manufacturer's decision to engage in remanufacturing operations in-house or outsource them to an independent remanufacturer?

- Which channel structure is beneficial for the economy and environment? 
From a research perspective, although the importance of carbon cap-and-trade regulations has been recognized (refer to [6] and references therein), studies have not paid attention to what effects carbon cap-and-trade regulations have on a manufacturer's remanufacturing operations with the flexibility to engage them in-house or outsource them to third-party remanufacturers. On the contrary, although much literature has paid attention to the strategic choice regarding the manufacturer's flexibility to remanufacture in-house or outsource (refer to [17] and references therein), it has ignored the importance of carbon cap-and-trade regulations. Therefore, our main aim is to understand what effects carbon cap-and-trade regulations have on a manufacturer's operation management when producing new and remanufactured products. In particular, the manufacturer has the flexibility to remanufacture in-house or outsource the process to third-party remanufacturers, which not only affects the economic performance but also sustainability issues $[17,18]$.

In particular, our analysis reveals that from an economic performance perspective, engaging in remanufacturing operations in-house is always beneficial for the manufacturer. Surprisingly, from an environmental angle, our analysis reveals that although the manufacturer has a higher incentive to reduce the carbon emissions per remanufactured unit in Model $\mathrm{H}$, the total carbon emissions may be higher than that the value in Model R, because the sales volume of remanufactured products is much higher in the former. Therefore, we suggest that under carbon cap-and-trade regulations, environmental groups and agencies should not only take effective measures to stimulate the incentive of reduce the carbon emissions per unit but must also take care regarding the supply chain structure to limit the volume effect.

This paper is organized as follows: Section 2 reviews the literature and explains our contributions in more detail, Section 3 outlines our assumptions for model development, Section 4 analyzes our results in terms of the economic and environmental performance, and Section 5 presents a discussion and provides future research directions.

\section{Literature Review}

In recent decades, the carbon cap-and-trade mechanism has had significant importance in green supply chain management-related new product production. For example, Klingelhofer [19] provided an approach for valuating investments in end-of-pipe-technologies with special regard to an emissions trading scheme, showing that tradable permits have several effects on an investment and do not always encourage environmentally beneficial investments. Du et al. [20] solved the manufacturer's multi-product joint pricing and production problem, with consumers valuing the low-carbon product more highly than the ordinary product, and they found that cap-and-trade may constrain the total carbon emissions and promote low-carbon production simultaneously. Lei et al. [21] investigated five channel structures for manufacturers under consumers' low-carbon preference and showed that if the consumers' low-carbon preference grows, dual channels can be chosen to satisfy the increasing online and offline demands. Xu et al. [22] analyzed a newsvendor problem with partial demand information under two kinds of carbon emission regulations, in which only the mean and variance of the demand distribution were known. The result indicated that compared with carbon emission parameters, the demand information parameters have a greater effect on the optimal worst-case expected profit and smaller effect on carbon emissions under carbon cap regulation. Manikas and Kroes [23] presented a new forwardbuying heuristic, which was designed for firms that need to purchase emissions allowances via auctions, and it reduces the impact of emissions allowance acquisitions on the firms' financial performance. The results indicated that the heuristic could be readily adopted by any firm that is required to procure emissions allowances via open markets in an effort to improve the firm's profitability. Monfared et al. [24] examined a bi-objective continuous review inventory control model with order splitting among multiple suppliers, where both expected costs and carbon emissions per unit time are minimized, and they showed that the delivery policy and supplier selection both have strong effects on the economic and environmental performance. They also demonstrated that a good approximation of the Pareto 
front is crucial for accurately comparing delivery scheduling policies. Although there have been increasing studies on operation management considering carbon emissions regulations in recent years, these studies have mainly focused on the forward manufacturing process rather than remanufacturing issues [6]. The above literature has recognized the fact that the carbon cap-and-trade mechanism has had significant importance in green supply chain management-related new product production; however, little attention has been paid to the effects that carbon cap-and-trade regulations have on a manufacturer's closed-loop control decisions when producing new and remanufactured products. In this paper, we develop two possible models related to the carbon cap-and-trade mechanism and highlight the manufacturer's remanufacturing operations, with the flexibility to engage them in-house or outsource them to third-party remanufacturers. Therefore, we complement the above literature to highlight the manufacturer's optimal closed-loop control under cap-andtrade regulation.

The second related stream of the literature is on green supply chain managementassociated remanufacturing. In particular, Zhang et al. [11] developed two models in which a manufacturer produces new products but outsources remanufacturing operations to an authorized remanufacturer. They intended to highlight two potential strategies for dealing with the cannibalization from remanufacturing outsourcing: (1) collecting used cores from consumers or (2) remarketing all remanufactured products to consumers. Yan et al. [17] addressed the problem of whether OEMs should also outsource their reverse channels to third-party remanufacturers when outsourcing remanufacturing and showed that the OEM conducting take-back operations itself can achieve better outcomes overall for all economic, social, and environmental situations. Agrawal et al. [25] investigated whether and how the presence of remanufactured products and the identity of the remanufacturer influence the perceived value of new products through a series of behavioral experiments and demonstrated that the presence of products remanufactured and sold by the original equipment manufacturer can reduce the perceived value of new products by up to $8 \%$. Shi et al. [26] considered a firm consisting of two divisions: one responsible for designing and manufacturing new products and the other responsible for remanufacturing operations. The firm sells these new and remanufactured products either directly to the consumer or through an independent retailer. Wu and Zhou [27] developed a game theoretical model to revisit the effects of these policies in a closed-loop supply chain in which one supplier sells a component that cannot be remanufactured to one original equipment manufacturer and one third-party remanufacturer. Although the above literature demonstrates that the manufacturer has the flexibility to conduct remanufacturing operations in-house or outsource them to an independent remanufacturer, it does not pay any attention to the importance of carbon cap-and-trade regulations on remanufacturing. However, the cap-and-trade regulation is a market-based mechanism that sets a carbon emission cap for a firm, above which the firm should purchase extra carbon emissions permits from a carbon market; otherwise, it can sell the surplus carbon emissions permits. Such a mechanism would impact manufacturers' remanufacturing decisions, as it increases the cost of carbon emissions. Therefore, we contribute to the above literature by further addressing what effects carbon cap-and-trade regulations have on a manufacturer's closed-loop control, with the flexibility to engage it in-house or outsource it to thirdparty remanufacturers.

To the best of our knowledge, several studies have recently begun to analyze the implications of carbon cap-and-trade regulations on remanufacturing operations. In particular, Chai et al. [6] explored the possibility of a monopolistic manufacturer being involved in both manufacturing and remanufacturing to profit under the carbon cap-and-trade mechanism in a single period and found that carbon cap-and-trade can be valuable for remanufacturing in both the ordinary market and the green market. Therefore, they suggested that policy makers should focus on carbon trading prices to reduce carbon emissions and improve the manufacturers' profits in both markets. More recently, Chen and Ulya [28] investigated the behavior of supply-chain members in green supply chain management under the reward-penalty mechanism from the government and showed that when con- 
sidering decentralized channels, under the reward-penalty mechanism, the manufacturer collects used products, which is deemed more effective when it cannot offer a higher transfer price. We differ from them in important ways. First, as mentioned earlier, although the importance of carbon cap-and-trade regulations on remanufacturing operations has been recognized, they do not allow the manufacturer to have the flexibility to engage them in-house or outsource them to third-party remanufacturers. Therefore, we complement them by addressing the importance of carbon cap-and-trade regulations in manufacturer's remanufacturing operations with the flexibility to engage them in-house or outsource them to third-party remanufacturers. Second, besides highlighting the manufacturer's economic profitability under carbon cap-and-trade regulations, we also pay attention to the optimal levels of incentives in carbon emissions reduction per unit and the total quantity of carbon emissions in related green markets.

To explain our contributions in more detail, we provide a comparison with some of the main related studies to highlight the research gaps and contributions (Table 1).

Table 1. Contributions compared to existing literature.

\begin{tabular}{cccc}
\hline Research Issues & $\begin{array}{c}\text { Manufacturing } \\
\text { Decisions }\end{array}$ & $\begin{array}{c}\text { Remanufacturing } \\
\text { Decisions }\end{array}$ & $\begin{array}{c}\text { Carbon Cap-and-Trade } \\
\text { Regulations }\end{array}$ \\
\hline This paper & $\sqrt{ }$ & $\sqrt{ }$ & \\
\hline $\begin{array}{c}\text { Klingelhofer [19], Du et al. [20], Lei et al. [21], Xu et al. } \\
\text { [22], Manikas and Kroes [23], Monfared et al. [24] }\end{array}$ & $\sqrt{ }$ & $\sqrt{ }$ \\
\hline $\begin{array}{c}\text { Zhanget al. [11], Yan et al. [17], Agrawal et al. [25], Shi } \\
\text { et al. [26], Wu and Zhou [27] }\end{array}$ & $\sqrt{ }$ & $\sqrt{ }$ & $\times$ \\
\hline
\end{tabular}

\section{Model Description and Assumptions}

The primary goal of this paper is to understand what effect carbon cap-and-trade regulations have on green supply chain management when producing new and remanufactured products. Hence, we consider two possible remanufacturing scenarios related to our research: (1) the manufacturer engages in the remanufacturing operations in-house (Model $\mathrm{H}$ ) or (2) outsources them to an independent remanufacturer (Model R). In both models, to highlight the carbon cap-and-trade regulatory administration, we use $C$ to represent the carbon emissions cap, which is the carbon emissions constraint for the manufacturer when producing new and remanufactured products.

Given the above framework, we will use the following notation: $c_{n}$ denotes the unit cost of producing a new product, while $c_{r}$ refers to the unit cost of remanufacturing a remanufactured one; $p_{n}$ and $p_{r}$ denote the market clear prices of the new and remanufactured products, respectively; $w_{r}$ is the unit wholesale price for the new product; and $m$ is the unit carbon trading price. Table 2 summarizes the main notations used in this paper.

Table 2. Main notations used in this paper.

\begin{tabular}{cc}
\hline Notation & Definition \\
$\gamma$ & The consumer value discount for remanufactured products \\
$c_{n} / c_{r}$ & The unit cost for the new $/$ remanufactured product \\
$p_{n}^{i} / p_{r}^{i}$ & The price of the new $/$ remanufactured product in Model $\mathrm{i}, i \in(H, R)$ \\
$q_{n}^{i} / q_{r}^{i}$ & The quantity of new / remanufactured products in Model $\mathrm{i}$ \\
$w_{r}^{i}$ & The wholesale price charged for the remanufactured unit in Model $\mathrm{R}$ \\
$\pi_{j}^{i}$ & The player $j^{\prime}$ s profit in Model $i$, where $j \in(M, R)$ denotes the \\
$e_{n}$ & manufacturer, remanufacturer, and industry, respectively \\
$m$ & The environmental impact of a new product \\
$s$ & The unit carbon trading price
\end{tabular}

The main assumptions will now be provided. 
Assumption 1. There are two lives for any product: It is a new one at its first appearance, and it is a remanufactured product for its second appearance in the same market.

Assumption 1 is quite common in remanufacturing research [15,29,30]. Accordingly, in both our models, we restrict the quantities of remanufactured products so that they are lower than the volume of new products sold in the market. That is, we assume that all remanufactured products are derived from remanufactured cores, which come from the new product sales.

In practice, many brand name environmental groups and agencies usually encourage manufacturers to extend their responsibility for remanufacturing issues. For example, The Waste Electrical and Electronic Equipment (WEEE) directive in the E.U. promotes all original equipment to "extended producer responsibility" to treat and recycle their new products when they are no longer wanted by consumers. As such, we assume that, in both our models, the manufacturer is always the Stackelberg leader, whose incentives in emission reduction depend on investment, that is,

Assumption 2. The unit carbon emissions for producing a new product are represented by $e_{n}$, while the unit carbon emissions for remanufacturing a core are represented by $e_{n}-s$, where $s$ denotes the level of incentives of reducing carbon emissions.

Assumption 2 means that the remanufacturing can bring great environmental benefits, since it consumes less energy than manufacturing new products. This argument is supported by prior empirical research. For example, Giutini and Gaudette [31] stated that in terms of energy consumption, remanufacturing a core consumes only about $15 \%$ of the energy used to make the product from scratch. In addition, Xerox successfully reduced $42 \%$ emissions and 31\% energy consumptions by 2012 through engaging in remanufacturing operations.

Assumption 3. The incentive of reducing carbon emissions is influenced by the level of investment, which is a convex cost function of $\frac{s^{2}}{2}$.

In prior literature related to remanufacturing, Bai et al. [32], incorporating carbon emission reduction into a make-to-order supply chain, used similar investment functions to analyze the carbon emission reduction under cap-and-trade and carbon tax regulations. Similar forms of investment functions have also been widely used in operations literature-related research and development (e.g., Veldman and Gaalman [33] and Miremadi et al. [34]). This paper investigates carbon emission reduction incentives that are similar to those in the above studies under cap-and-trade and carbon tax regulations.

Assumption 4. A consumer's utility from the remanufactured product is devalued by a factor $\gamma(\in[0,1])$ of that from the new product. In addition, a consumer's utility for a new product is heterogeneous, which is uniformly distributed for the interval $[0,1]$.

Similar to references [11,27], we assume that consumers' willingness-to-pay for remanufactured products is lower than that for new ones. This assumption is supported by empirical evidence [25,35]. For example, Guide et al. [35] stated that according to auction results for commercial products, consumers' willingness-to-pay for remanufactured products is $9.7 \%$ lower than that for new products. This price differentiation between remanufactured and new products may be consistent with the fact that producing a remanufactured product is less costly than making a new one [17].

It should be noted that if the factor $\gamma=1$, the consumer is willing to pay as much for a remanufactured product as a new one. However, if $\gamma=0$, all consumers are willing to pay nothing for any remanufactured product. This differentiation not only reflects the price differentiation between remanufactured and new products but also contributes to the problem of cannibalization between both products.

Based on Assumption 4, we can derive all consumers' willingness-to-pay for the new product as $U_{n}=v-p_{n}$, where $v$ is the consumers' valuation and $p_{n}$ is the price charged to the consumers. Given that the consumer's utility from the remanufactured product is 
devalued by a factor $\gamma$ of that from the new product, the consumer's willingness-to-pay for the remanufactured product is $U_{r}=\gamma v-p_{r}$. From the above two willingness-to-pay functions, we can divide consumers into two groups: When the consumers' willingness-topay $U>\frac{\left(p_{n}-p_{r}\right)}{(1-\gamma)}$, consumers choose to purchase the new product, because they can obtain a higher net utility from the new product. However, when $0<U<\frac{\left(p_{n}-p_{r}\right)}{(1-\gamma)}$, the consumers in this interval prefer the remanufactured product to new one. Figure 1 illustrates the consumers' willingness-to-pay for both new and remanufactured products, respectively.

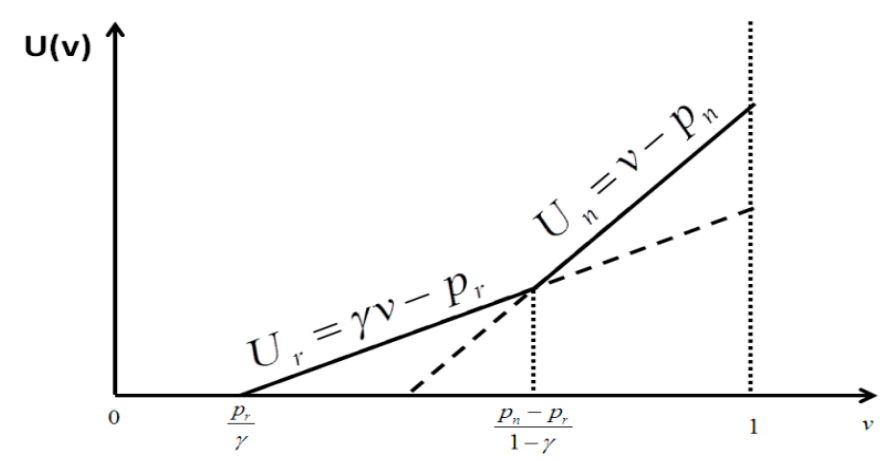

Figure 1. Willingness-to-pay functions for consumers.

Based on the above analysis, we can obtain the demand functions for the new and remanufactured products as follows:

$$
\begin{gathered}
p_{n}=1-q_{n}-\gamma q_{r} \\
p_{r}=\gamma\left(1-q_{n}-q_{r}\right)
\end{gathered}
$$

Assumption 5. The product previously existed in the market and thus all decisions are analyzed in a single-period model.

To conduct a clear comparison of the two models, as in Zhang et al. [11] and Savaskan et al. [29], we only pay attention to a one-period model with all used cores having previously existed in the market and exhibiting the possibility to be remanufactured.

\section{Model Formulation and Solution}

\subsection{Manufacturer Undertakes Remanufacturing In-House (Model H)}

We first highlight Model $\mathrm{H}$, in which the manufacturer engages in the remanufacturing operations in-house. It should be noted that in the U.S. remanufacturing market, some brand-name manufacturers, including HP, Xerox, General Electric Company, and Ford, have undertaken their remanufacturing operations in-house. For example, to reduce their environmental impacts and make information technology (IT) equipment accessible to more people, HP extended the life of IT hardware through repair and remanufacturing programs all over the world [36].

Since both the new and remanufactured products are made by the manufacturer itself, the manufacturer's objective is to maximize the profit by choosing the optimal quantities of new products $\left(q_{n}\right)$ and remanufactured units $\left(q_{r}\right)$. Therefore, the manufacturer's problem is:

$$
\max _{q_{n}, q_{r}} \pi_{M}^{H}=\left(p_{n}-c_{n}\right) q_{n}+\left(p_{r}-c_{r}\right) q_{r}+m\left(C-e_{n} q_{n}-\left(e_{n}-s\right) q_{r}\right)-s^{2} / 2 .
$$

The first two terms of Equation (2) are the profits made when selling new and remanufactured products, while the last term is the profit or cost of the carbon trading; that is, if the manufacturer's carbon emissions are lower than the threshold of the carbon emission cap, then it can sell surplus carbon emissions. However, if its carbon emissions are above the threshold of the carbon emission cap, then it should purchase inadequate carbon emissions 
to support the production and/or remanufacturing businesses. The demand functions for the new and remanufactured product are given in Equation (2).

Backward induction is employed to identify the optimal outcomes of Model H. We first perform optimization in Equation (2), which provides $q_{r}^{H}$ and $q_{n}^{H}$ as follows:

$$
\begin{gathered}
q_{n}^{H}=\frac{\gamma-1-c_{r}+m s+c_{n}}{2(\gamma-1)} \\
q_{r}^{H}=\frac{c_{r}+m e_{n}-m s-\gamma c_{n}-\gamma m e_{n}}{2 \gamma(\gamma-1)} .
\end{gathered}
$$

Substituting $q_{r}^{H}$ and $q_{n}^{H}$ into Equation (2) and performing the function with maximization yields the manufacturer's optimal carbon emissions reduction efforts as

$$
s^{H *}=\frac{m\left(\gamma m e_{n}+\gamma c_{n}-m e_{n}-c_{r}\right)}{2 \gamma-2 \gamma^{2}-m^{2}} .
$$

Substituting $s^{H *}$ into $q_{r}^{H}$ and $q_{n}^{H}$, we can obtain all optimal outcomes in Model $\mathrm{H}$.

\begin{tabular}{|c|c|}
\hline & Remanufacturing Undertaken In-House (Model H) \\
\hline & 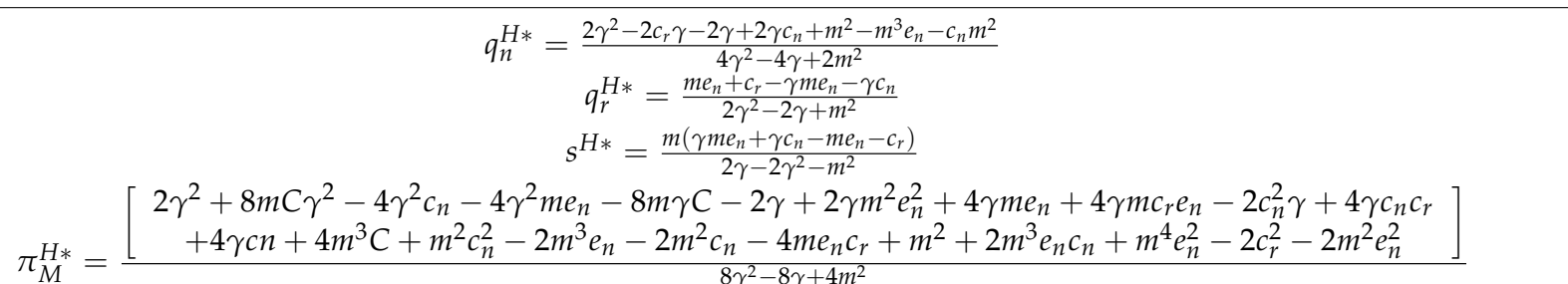 \\
\hline & Remanufacturing Outsourced to a Remanufacturer (Model R) \\
\hline$\pi_{M}^{R *}=$ & $\begin{array}{c}q_{n}^{R *}=\frac{3 \gamma^{2}-\gamma^{2} m e_{n}-\gamma^{2} c_{n}+8 \gamma c_{n}-8 \gamma-2 c_{r} \gamma+6 \gamma m e_{n}-2 m^{3} e_{n}-2 c_{n} m^{2}+2 m^{2}}{6 \gamma^{2}-16 \gamma+4 m^{2}} \\
q_{r}^{R *}=\frac{2\left(\gamma c_{n}+\gamma m e_{n}-c_{r}-m e_{n}\right)}{8 \gamma-3 \gamma^{2}-2 m^{2}} \\
w^{R *}=\frac{\left[\gamma^{3} c_{n}-8 \gamma m e_{n}+2 \gamma^{2} m e_{n}+8 c_{r} \gamma+\gamma^{3} m e_{n}-4 c_{r} \gamma^{2}-4 c_{r} m^{2}-8 \gamma^{2}+3 \gamma^{3}+2 \gamma m^{2}+2 \gamma c_{n} m^{2}+2 \gamma m^{3} e_{n}\right]}{2\left(3 \gamma^{2}-8 \gamma+2 m^{2}\right)} \\
s^{R *}=\frac{2 m\left(m e_{n}-\gamma c_{n}-\gamma m e_{n}+c_{r}\right)}{2 m^{2}-8 \gamma+3 \gamma^{2}} \\
\pi_{R}^{R *}=\frac{4\left(\gamma c_{n}+\gamma m e_{n}-c_{r}-m e_{n}\right)^{2} \gamma}{\left(3 \gamma^{2}-8 \gamma+2 m^{2}\right)^{2}} \\
2 m^{2}-8 c_{r} m e_{n}-8 \gamma+2 m^{2} c_{n}^{2}-6 \gamma^{2} m e_{n}+3 \gamma^{2}-4 m^{3} e_{n}-4 c_{n} m^{2}-6 \gamma^{2} c_{n}+16 \gamma c_{n}+16 \gamma m e_{n}-2 \gamma^{2} c_{n} m e_{n}+8 \gamma m e_{n} c_{r} \\
-8 \gamma c_{n} m e_{n}-\gamma^{2} c_{n}^{2}-\gamma^{2} m^{2} e_{n}^{2}-4 c_{r}^{2}-4 m^{2} e_{n}^{2}+2 m^{4} e_{n}^{2}+12 m \gamma^{2} C+8 \gamma c_{n} c_{r}+4 m^{3} e_{n} c_{n}-32 m \gamma-8 \gamma c_{n}^{2}+8 m^{3} C \\
12 \gamma^{2}-32 \gamma+8 m^{2}\end{array}$ \\
\hline
\end{tabular}
Table 3 summarizes all of the main decisions regarding the manufacturer's optimal choices.

Table 3. Equilibrium decisions and profits.

\subsection{Manufacturer Outsources the Remanufacturing to a Remanufacturer (Model R)}

In Model R, the manufacturer only focuses on new product manufacturing, while its remanufacturing operations are outsourced to independent remanufacturers. For example, in the U.S. remanufacturing market, some OEMs, such as IBM, Apple, Cummins, and Land Rover, have outsourced their remanufacturing operations to independent remanufacturers. Take Land Rover as an example: in 2005, Land Rover announced its decision to outsource its remanufacturing business to Caterpillar, which is one of the world's largest remanufacturers. In the agreement, the Caterpillar Remanufacturing Services provided integrated solutions for Land Rover on remanufacturing development and operation management [37].

When the remanufacturing operations are outsourced to an independent remanufacturer, the optimal quantities of remanufactured products are determined by the remanufacturer. Therefore, under Model R, the independent remanufacturer's problem can be written as follows:

$$
\max _{q_{r}} \pi_{R}^{R}=\left(p_{r}-w-c_{r}\right) q_{r}
$$


It should be noted that the selling cost for the remanufacturer includes the cost of remanufacturing and the wholesale price of used cores set by the manufacturer, who sells the new products in the same market. Thus, the manufacturer's problem is

$$
\max _{q_{n}} \pi_{M}^{R}=\left(p_{n}-c_{n}\right) q_{n}+w q_{r}+m\left(C-e_{n} q_{n}-\left(e_{n}-s\right) q_{r}\right)-s^{2} / 2 .
$$

Similar to the manufacturer's profit in Model $\mathrm{H}$, the first term of Equation (6) represents the profits of selling new products, and the second term is the profitability of remanufactured product wholesales, while the last term is the profit or cost of the carbon trading. It should be noted that it is the manufacturer who is responsible for the carbon emissions reduction, which is consistent with the fact that many brand-name environmental groups and agencies usually encourage manufacturers to extend their responsibility to remanufacturing issues.

Again, backward induction is employed to identify the optimal outcomes of Model R. By performing optimization in Equations (5) and (6), we can obtain $q_{r}^{H}$ and $q_{n}^{H}$ as follows:

$$
\begin{aligned}
& q_{n}^{R}=\frac{2 c_{n}+2 m e_{n}+\gamma-c_{r}-2-w}{\gamma-4} \\
& q_{r}^{R}=\frac{\gamma-2 c_{r}+\gamma_{n}+\gamma m e_{n}-2 w}{\gamma(4-\gamma)}
\end{aligned} .
$$

Substituting $q_{r}^{H}$ and $q_{n}^{H}$ into Equation (6), we can obtain the manufacturer's problem as follows:

$$
\max _{w, s} \pi_{M}^{R}=\left(p_{n}-c_{n}\right) q_{n}+w q_{r}+m\left(C-e_{n} q_{n}-\left(e_{n}-s\right) q_{r}\right)-s^{2} / 2 .
$$

Performing Equation (8) with maximization yields the following optimal wholesale price and carbon emissions reduction efforts:

$$
w^{R *}=\frac{\left[\begin{array}{c}
\gamma^{3} c_{n}-8 \gamma m e_{n}+2 \gamma^{2} m e_{n}+8 c_{r} \gamma+\gamma^{3} m e_{n}-4 c_{r} \gamma^{2} \\
-4 c_{r} m^{2}-8 \gamma^{2}+3 \gamma^{3}+2 \gamma m^{2}+2 \gamma c_{n} m^{2}+2 \gamma m^{3} e_{n}
\end{array}\right]}{\left.s^{R *}=\frac{2 m\left(3 m_{n}-\gamma c_{n}-2 m^{2}\right)}{2 m^{2}-8 \gamma+3 \gamma^{2}}\right)} .
$$

Substituting $s^{R *}$ and $w^{R *}$ into $q_{r}^{R}$ and $q_{n}^{R}$, we can obtain all optimal outcomes in Model $R$. All of the main decisions regarding the manufacturer's optimal choices are summarized in Table 3.

\section{Analysis and Discussion}

To ensure that all optimal decisions are positive, as in Zhang et al. [11] and He et al. [37], we derive the following assumption:

Assumption 6. In both models, the remanufacturing cost should be in the interval of $\frac{2 \gamma^{2}-2 \gamma-4 \gamma c_{n}+m^{2}-m^{3} e_{n}-c_{n} m^{2}+2 \gamma m e_{n}-2 m e_{n}}{2(\gamma+1)}<c_{r}<\gamma c_{n}+\gamma m e_{n}-m e_{n}$.

It should be noted that if the remanufacturing cost is too high, i.e., $c_{r} \geq \gamma c_{n}+\gamma m e_{n}-$ $m e_{n}$, the manufacturer or independent remanufacturer will not remanufacture any used cores, that is, $q_{r}^{H *}<0, q_{r}^{R *}<0$. On the other hand, when the remanufacturing cost is too small, i.e., $c_{r} \leq \frac{2 \gamma^{2}-2 \gamma-4 \gamma c_{n}+m^{2}-m^{3} e_{n}-c_{n} m^{2}+2 \gamma m e_{n}-2 m e_{n}}{2(\gamma+1)}$, this leads to two results: First, the remanufacturing cost is small, which results in a lower price of the remanufactured product. The lower the price of the remanufactured product, the fiercer the cannibalization of new product sales. Second, since the remanufacturing cost is small, selling remanufactured products is a profitable business. The more remanufactured product sales in the market, the smaller the potential market for new products. Therefore, when the remanufacturing cost is too small, the manufacturer will be reluctant to offer enough new products, leading to the other extreme case (i.e., $q_{n} \leq q_{r}$ ). 


\subsection{Analysis on Optimal Decisions}

Before focusing the analysis on the research questions, we need to understand the difference between the optimal decisions of both models. It should be noted that this comparison adds a little more intuition through several propositions. In particular, we provide the following proposition (for proof, see Appendix A):

Proposition 1. The manufacturer provides fewer quantities of new products in Model $H$ than in Model $R$; that is, $q_{n}^{H}<q_{n}^{R}$.

Proposition 1 indicates that compared with outsourcing the remanufacturing operations to an independent remanufacturer, undertaking the remanufacturing operations in-house results in lower quantities of new products. This can be interpreted from two perspectives. On the one hand, in Model H, both new and remanufactured products are offered by the manufacturer, and this allows the manufacturer to have a monopolistic position to trade off benefits from both products. In addition, selling fewer units of new products in the market allows the monopolist to achieve price discrimination between both products. On the other hand, in Model $\mathrm{R}$, only the new products are offered by the manufacturer; as such, to maximize the profits, the manufacturer has to sell more units of new products when the remanufacturing operations are outsourced to an independent remanufacturer.

We now turn our attention to the difference in the quantities of remanufactured products based on the outcomes in Table 3 and provide the following proposition:

Proposition 2. The equilibrium quantities of remanufactured products in Model $H$ are higher than in Model $R$; that is, $q_{r}^{H}>q_{r}^{R}$.

Surprisingly, Proposition 2 reveals that although selling the remanufactured products is the only source of the independent remanufacturer's profits, the remanufacturer would like to provide fewer quantities of the remanufactured one. The intuition behind the results is as follows. In Model R, selling remanufactured products is indeed the only source of the independent remanufacturer's profit. As such, outsourcing the remanufacturing operations would create a fiercer cannibalization problem for the manufacturer's new product sales. Anticipating that, as Proposition 1 shows, the manufacturer has an incentive to sell more quantities of new products, this strategy can decrease the potential market for remanufactured products and limit the cannibalization problems from remanufactured product sales. As such, as Proposition 2 shows, the optimal quantities of remanufactured products in Model $\mathrm{H}$ are higher than in Model R, that is, $q_{r}^{H}>q_{r}^{R}$.

To obtain a more detailed understanding on the difference between the optimal decisions in both models, we further find that the total quantities of both products in Model $\mathrm{H}$ are higher than in Model R; that is, $q_{n}^{H}+q_{r}^{H}>q_{n}^{R}+q_{r}^{R}$. Based on Propositions 1 and 2, we can conclude that although the manufacturer provides fewer quantities of new products in Model H than in Model R (see Proposition 1), the manufacturer will offer so many units of the remanufactured product that this can "compensate" for the quantity "loss" in new product sales. The manufacturer always has a higher incentive to provide more units of remanufactured products when the remanufacturing operations are untaken in-house.

\subsection{Analysis on the Economic Performance}

We are now in a position to analyze the first research questions posed at the beginning of this paper: Under the carbon cap-and-trade mechanism, should the manufacturer engage in the remanufacturing operations in-house or outsource them to an independent remanufacturer? Comparing the difference between the manufacturer's profits in both models, we answer this question as follows:

Proposition 3. Undertaking the remanufacturing operations in-house is always beneficial for the manufacturer, $\pi_{M}^{H}>\pi_{M}^{R}$. 
Undertaking remanufacturing operations in-house can allow the company to earn more because it does not necessarily share the profits with an independent remanufacturer [38]. Proposition 3 confirms this conventional wisdom. It should be noted that when remanufacturing is undertaken in-house, both new and remanufactured products are distributed by the manufacturer, providing the manufacturer with a monopolistic position to achieve price discrimination between both products and to obtain the monopoly profits. In addition, since the unit cost for remanufactured products is lower than that of making a new product, the marginal profits from selling remanufactured products is quite a profitable business. As such, we can observe that to obtain more profits from the remanufacturing, the manufacturer would provide fewer quantities of new products in Model $\mathrm{H}$ than in Model R. This strategy can not only lead to higher prices for new products, but it can also result in a larger potential market for remanufactured products.

On the other hand, when the remanufacturing operations are outsourced to an independent remanufacturer, the new products are offered by the manufacturer and the remanufactured ones are distributed by the independent remanufacturer. As such, outsourcing remanufacturing operations to an independent remanufacturer would create competition between the manufacturer and the remanufacturer and lead to a loss in the manufacturer's profits.

We have answered the first question from the manufacturer's perspective. We will now analyze which remanufacturing scenario (in-house or outsourcing) is better for the industry in terms of the economic benefits. Based on the outcomes in Table 3, we offer the following proposition:

Proposition 4. Undertaking the remanufacturing operations in-house is always beneficial for the industry, $\pi_{T}^{H}>\pi_{T}^{R}$.

Proposition 3 indicates that undertaking remanufacturing operations in-house can allow a company to earn more because it does not necessarily share the profits with the independent remanufacturer. However, Proposition 4 further reveals that the industry profits in Model $\mathrm{R}$ (equal to the profits of the manufacturer plus the profits of the remanufacturer) are lower than in Model $\mathrm{H}$ (equal to the profits of the manufacturer). Compared to undertaking remanufacturing in-house, outsourcing the operations to an independent remanufacturer not only hurts the manufacturer's profits but may also be detrimental to the industry.

The intuition behind this result is as follows. On the one hand, from the perspective of selling new products, all new products in both models are produced by the manufacturer. The main difference is that the manufacturer distributes the remanufactured products in Model H; however, all remanufactured ones are made available by the independent remanufacturer. Such competition from the remanufacturer in Model R cannibalizes the new product sales and hurts the manufacturer's profits from new product sales. On the other hand, from the perspective of remanufactured product marketing, in Model $\mathrm{H}$, all remanufactured products are directly distributed by the manufacturer; however, in Model R, the remanufactured products are offered by the remanufacturer. As such, outsourcing the remanufacturing operations to the remanufacturer induces the classic double marginalization problems between the manufacturer and remanufacturer. In this case, both the manufacturer (who sets the wholesale price for the used cores) and the remanufacturer (who sets the selling price for the remanufactured products) independently seek to maximize their own profit, resulting in lower profits than when all remanufactured products are directly distributed by the manufacturer.

\subsection{Analysis on the Environmental Sustainability}

We acknowledge that defining environmental sustainability can be difficult. For example, in recent years, the European Union has issued a number of strategic documents that promote the circular economy. The circular economy approach emphasizes an even broader perspective on environmental sustainability that involves product, component, 
and material reuse; remanufacturing; refurbishment; repair; cascading and upgrading; and solar, wind, biomass, and waste-derived energy utilization throughout the product value chain and cradle-to-cradle life cycle, etc. To be consistent with the motivations of this paper, we define environmental sustainability as a result of industrial activity that depends on the total level of emissions of carbon dioxide. As such, we focus our attention on both the incentive of reducing the carbon emissions per unit and the total carbon emissions.

We will now answer the following question: Under the carbon cap-and-trade mechanism, which remanufacturing scenario (in-house or outsourcing) is better for our environment? We first turn our attention to the difference in the incentive of reducing the carbon emissions per unit and give the follow proposition:

Proposition 5. The manufacturer has a higher incentive to reduce the carbon emissions per remanufactured unit in Model $H$ than in Model $R$; that is, $s^{H}>s^{R}$.

Proposition 5 shows that compared to outsourcing the remanufacturing operations to the remanufacturer, undertaking the remanufacturing operations in-house would lead to a higher incentive to reduce the carbon emissions per remanufactured product. This can be interpreted as follows. On the one hand, when the remanufacturing operations are outsourced to the remanufacturer, the manufacturer's main revenue from remanufacturing is the whole price set per used core, while the cost for the remanufacturing outsourcing is the investment in emission reduction. As such, under the scenario of outsourcing the remanufacturing operations to a remanufacturer, given the wholesale price for the used cores, to maximize the profits from remanufacturing, the manufacturer's main task is to reduce the cost for the remanufacturing investment in emission reduction, which would result in a lower incentive to reduce the carbon emissions per remanufactured unit. On the other hand, as Proposition 2 shows, the equilibrium quantities of remanufactured products in Model H are higher than in Model R. Furthermore, such higher equilibrium quantities of remanufactured products lead to higher profits than in Model R (see Proposition 3). To prevent the total carbon emissions from exceeding the emission cap and maximize the profits from remanufacturing, the manufacturer's main task is to reduce the carbon emissions, which would result in a higher incentive to reduce the carbon emissions per remanufactured unit.

Based on the prior assumptions [6,22,28], we use $e_{t}^{i}=e_{n} q_{n}+\left(e_{n}-s\right) q_{r}$ to denote the total carbon emissions under Model $i$. Then, we provide a proposition on the difference in the total carbon emissions between both models, as follows:

Proposition 6. When $c_{r}<\widetilde{c}_{r}$, the total carbon emissions in Model H are higher than in Model $R$, that is, $e_{t}^{H}>e_{t}^{R}$; otherwise, the opposite is true.

Based on Propositions 5 and 6, we can conclude that although the manufacturer has a higher incentive to reduce the carbon emissions per remanufactured unit in Model $\mathrm{H}$, the total carbon emissions may be higher than in Model $\mathrm{R}$. The underlying intuition behind this result is as follows. If we compare outsourcing remanufacturing to the remanufacturer and undertaking remanufacturing in-house scenarios, the total carbon emissions are associated with the level of the incentive to reduce the carbon emissions per remanufactured unit. As Proposition 5 shows, the incentive to reduce the carbon emissions per remanufactured unit is actually higher in the latter scenario. However, as Proposition 2 shows, the manufacturer's sales volume of remanufactured products is much higher in the former. The sales volume effect is particularly notable when the unit cost for the remanufactured product is not pronounced, because selling remanufactured products is a quite profitable business.

\subsection{Numerical Analysis}

Thus far, we have analyzed the optimal strategy of remanufacturing under capand-trade regulation from a theoretical perspective. To obtain a more comprehensive 
review on our main results, we will now reanalyze the main theoretical results with numerical experiments.

In the numerical experiments, according to [6], [11], and [39], we picked the corresponding parameters $c_{n}=0.4, \gamma=0.8, e_{n}=0.2, C=1$, and $m=0.3$. We first compared the equilibrium quantities of new and remanufactured products. As illustrated in Figure 2a, the optimal quantities of new product in Model R are always higher than in Model H. As Proposition 1 shows, the manufacturer is more likely to provide fewer quantities of new products in Model $\mathrm{H}$ than in Model R. However, Figure 2b indicates that as Proposition 2 shows, the equilibrium quantities of remanufactured products in Model $\mathrm{H}$ are higher than in Model R. In addition, based on Figure 1, we can further conclude that as the unit cost for the remanufactured product increases, the difference in the equilibrium quantities of new and remanufactured products between both models decreases.

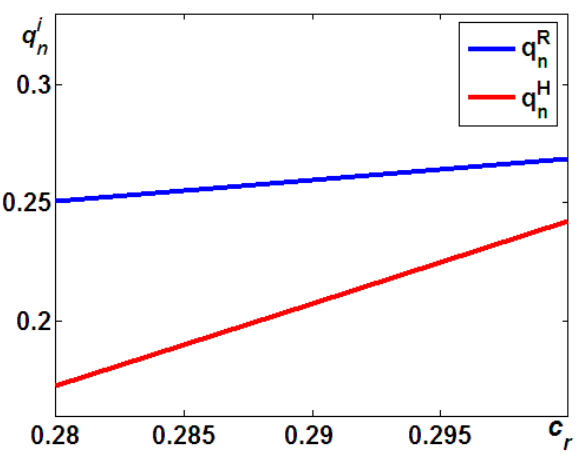

(a)

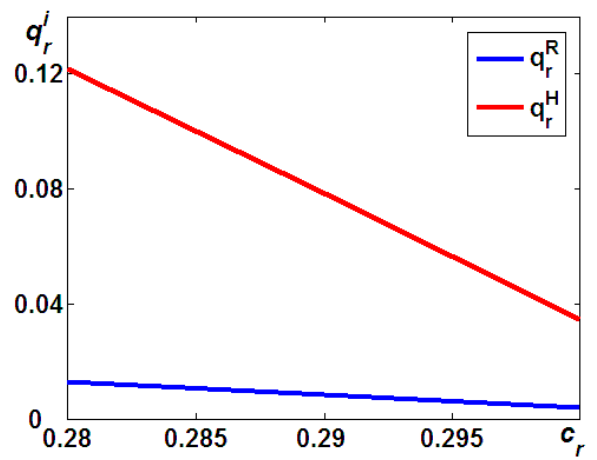

(b)

Figure 2. The difference in equilibrium quantities: (a) $q_{n}^{R}$ vs. $q_{n}^{H}$; (b) $q_{r}^{R}$ vs. $q_{r}^{H}$.

Interestingly, in terms of the difference in the economic performance between both models, we can find that, as displayed in Figure 3a, the manufacturer's profits in Model $\mathrm{H}$ and Model R both decrease with the unit cost for the remanufactured product. In particular, the equilibrium profits in Model $\mathrm{H}$ are always higher than in Model R. As Proposition 3 shows, compared to outsourcing the remanufacturing operations to a remanufacturer, undertaking the remanufacturing operations in-house is always beneficial for the manufacturer, $\pi_{M}^{H *}>\pi_{M}^{R *}$. In addition, as Figure $3 \mathrm{~b}$ shows, the industry profits in Model $\mathrm{R}$ (equal to the profits of the manufacturer plus the profits of the remanufacturer) are lower than in Model H (equal to the profits of the manufacturer). Compared to outsourcing the remanufacturing operations to the remanufacturer, undertaking the remanufacturing operations in-house is always beneficial for the industry, $\pi_{t}^{H *}>\pi_{t}^{R *}$. As such, based on Figure 3, undertaking the remanufacturing operations in-house would be beneficial for both the manufacturer and the industry.

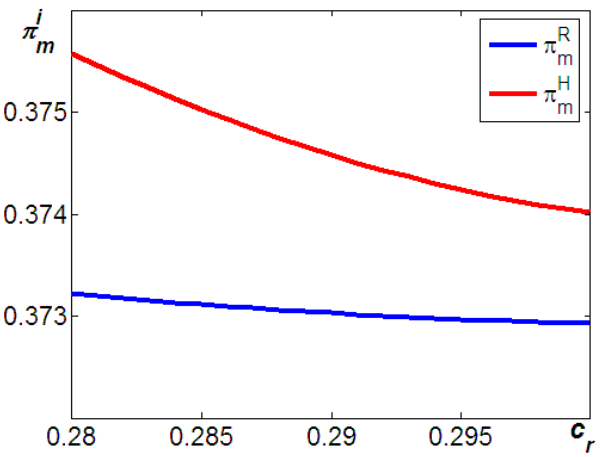

(a)

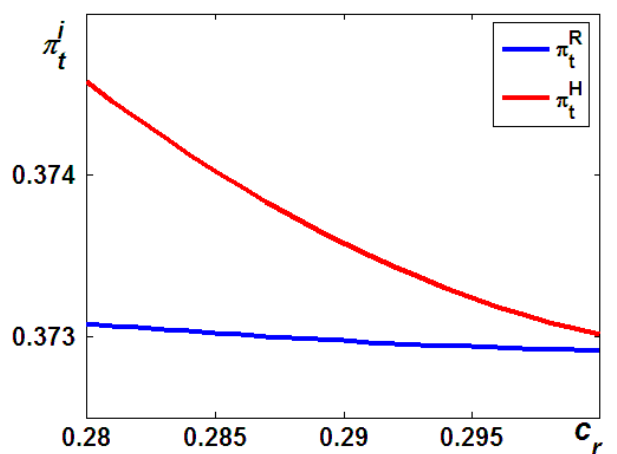

(b)

Figure 3. The difference in economic performance (a) $\pi_{m}^{R}$ vs. $\pi_{m}^{H}$; (b) $\pi_{t}^{R}$ vs. $\pi_{t}^{H}$. 
Finally, Figure 4 provides a numerical analysis on the difference in environmental sustainability. In particular, Figure 4 a reveals that as the unit cost for the remanufactured product increases, the difference in the environmental sustainability between both models decreases. Furthermore, for any cost for the remanufactured product, $c_{r}$, the level of the incentive to reduce the carbon emissions per remanufactured unit in Model $\mathrm{H}$ is higher than in Model R. However, Figure $4 \mathrm{~b}$ reveals several main generalizations on the total carbon emissions. First, as Proposition 6 shows, when the unit cost for the remanufactured product is not pronounced, i.e., $c_{r}<c_{r \Delta}$, the total carbon emissions in Model $\mathrm{H}$ are higher than in Model $\mathrm{R}$, that is, $e_{t}^{H}>e_{t}^{R}$; otherwise, the opposite is true. Second, as the unit cost for the remanufactured product increases, the difference in the total carbon emissions between the two schemes becomes narrow.

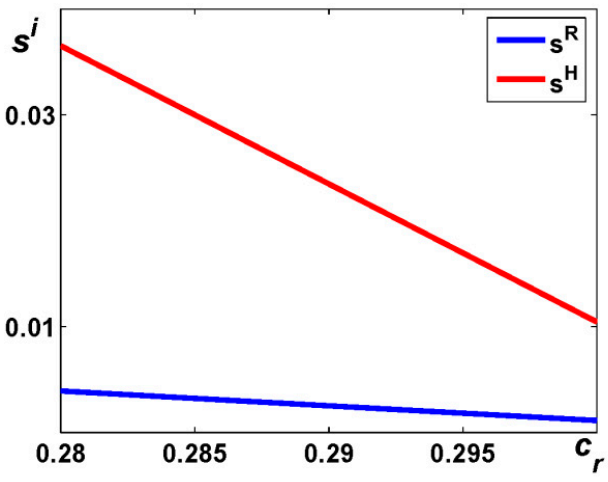

(a)

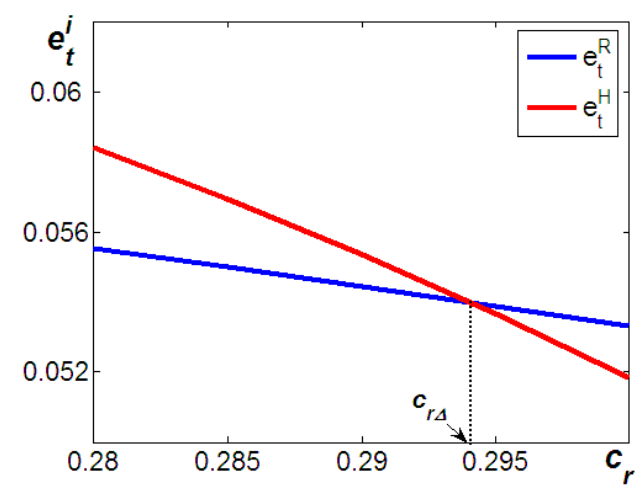

(b)

Figure 4. The difference in environmental sustainability: (a) $s^{R}$ vs. $s^{H} ;(\mathbf{b}) e_{t}^{R}$ vs. $e_{t}^{H}$.

\section{Conclusions}

Environmental consciousness has become important in our daily life [40]. In particular, the negative impact of warming in the climate system is undeniable due to its impact on the widespread melting of snow and ice, rising global average sea level, and problems associated with human health. As such, in March 18, 2015, seeking to spur other nations to get serious about climate change, President Obama ordered the federal government to cut its greenhouse gas emissions by as much as $28 \%$ over the following decade [4]. Similarly, the European Union (EU) announced its commitment to cut carbon emissions by at least $40 \%$ by 2030 [5].

In practice, carbon cap-and-trade regulation, as a market-based mechanism, has been proposed by many governments and organizations to mitigate carbon emissions. Such a carbon cap-and-trade mechanism naturally has a significant impact on the production plan management due to the potential costs or benefits associated with carbon emissions. However, on the other hand, remanufacturing is often considered to be a profitable and environmentally friendly approach because, compared with manufacturing, it can reduce production costs and carbon emissions. Therefore, it would be interesting to understand what effect carbon cap-and-trade regulations have on manufacturer's operations management when producing new and remanufactured products.

In particular, from a research perspective, although the importance of carbon cap-andtrade regulations has been recognized (e.g., [19-22]), such studies do not pay attention to the effect of carbon cap-and-trade regulations on a manufacturer's remanufacturing operations with the flexibility to engage them in-house or outsource them to third-party remanufacturers. However, on the other hand, in the U.S. remanufacturing industry, we can observe that some brand-name manufacturers, including HP, Xerox, General Electric Company, and Ford, have undertaken their remanufacturing operations in-house. However, several other OEMs, such as IBM, Apple, Cummins, and Land Rover, have outsourced their remanufacturing operations to independent remanufacturers. As such, in this paper, we contribute to the existing literature by further addressing what effect carbon cap-and-trade 
regulations have on a manufacturer's closed-loop control with the flexibility to engage it in-house or outsource it to third-party remanufacturers.

More specifically, based on the observation from current practice, we have developed two theoretical models that, under the carbon cap-and-trade mechanism, allow the manufacturer to engage in the remanufacturing operations in-house (Model $\mathrm{H}$ ) or outsource them to an independent remanufacturer (Model R). Using these two models, we have addressed several new and critical research questions:

1. How do carbon cap-and-trade regulations impact the manufacturer's decision on when it can engage in the remanufacturing operations in-house or outsource them to an independent remanufacturer?

2. Which channel structure is beneficial for the economy and environment?

Our paper provides several insights on what effect carbon cap-and-trade regulations have on green supply chain management when producing new and remanufactured products. In particular, we have found that from an economic performance perspective, engaging in the remanufacturing operations in-house is always beneficial for both the manufacturer and industry. Surprisingly, from an environmental angle, our analysis reveals that although the manufacturer has a higher incentive to reduce the carbon emissions per the remanufactured unit in Model $\mathrm{H}$, the total carbon emissions may be higher than in Model R. Therefore, our analysis suggests that under carbon cap-and-trade regulations, environmental groups and agencies should not only take effective measures to stimulate the incentive of reducing the carbon emissions per unit, but they must also take care with regard to limiting the volume effect.

We acknowledge that our models have some limitations. First, we consider two supply chain models involved with one manufacturer and one remanufacturer; however, in practice, the manufacturer usually outsources its remanufacturing operations to several authorized remanufacturers. Therefore, it would be interesting to conduct further explorations on the manufacturer outsourcing its remanufacturing operations to multiple authorized remanufacturers. Second, we assume that the selling price for carbon emissions always equals the purchasing price. Although this is quite a common assumption in prior research (e.g., Chai et al. [6]), it needs to be highlighted that the selling price may not always equal the purchasing price. For example, some firms can sell surplus carbon emissions permits at a relatively lower price to the intermediaries, who then charge a relatively higher price to the firm purchased extra carbon emissions permits. To our knowledge, there is no study highlighting the role played by the intermediaries under carbon cap-and-trade regulations. Finally, we developed two game theoretical models to study the effect carbon cap-and-trade regulations have on green supply chain management when producing new and remanufactured products, and it is worth addressing the above problem with empirical studies. In particular, our analysis suggests that under carbon cap-and-trade regulations, environmental groups and agencies should not only take effective measures to stimulate the incentive of reducing the carbon emissions per unit but must also take care with regard to limiting the volume effect.

Author Contributions: Writing—original draft preparation, Y.T.; writing—review and editing, B.F. Both authors have read and agreed to the published version of the manuscript.

Funding: This research was funded by the National Natural Science Foundation of China(71672020, 72072020, 71971043).

Institutional Review Board Statement: Not applicable.

Informed Consent Statement: Not applicable.

Data Availability Statement: Date sharing not applicable.

Conflicts of Interest: The authors declare no conflict of interest. 


\section{Appendix A. Proof for Proposition 1}

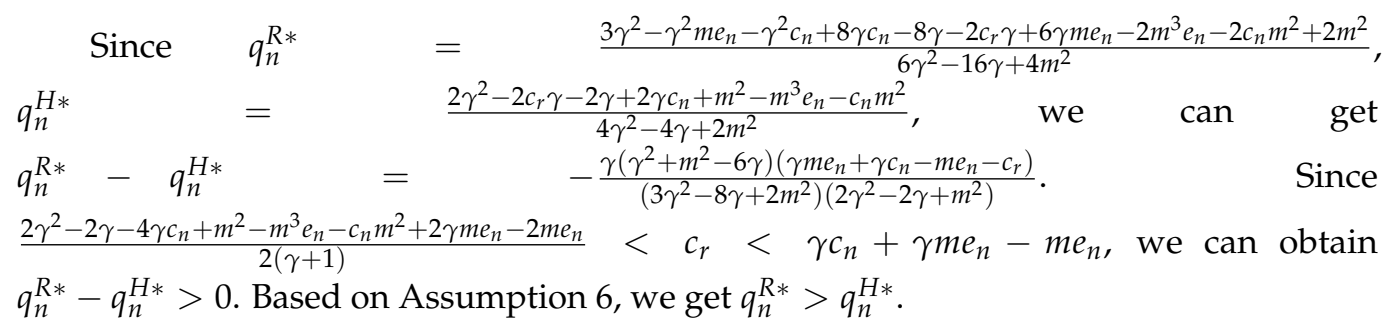

\section{Appendix B. Proof for Proposition 2}

Since $q_{r}^{H *}=\frac{m e_{n}+c_{r}-\gamma m e_{n}-\gamma c_{n}}{2 \gamma^{2}-2 \gamma+m^{2}}, q_{r}^{R *}=\frac{2\left(\gamma c_{n}+\gamma m e_{n}-c_{r}-m e_{n}\right)}{8 \gamma-3 \gamma^{2}-2 m^{2}}$, we can derive that $q_{r}^{R *}-q_{r}^{H *}=-\frac{\gamma\left(\gamma m e_{n}+\gamma c_{n}-m e_{n}-c_{r}\right)(\gamma+4)}{\left(3 \gamma^{2}-8 \gamma+2 m^{2}\right)\left(2 \gamma^{2}-2 \gamma+m^{2}\right)}$. $\quad$ Since $\frac{2 \gamma^{2}-2 \gamma-4 \gamma c_{n}+m^{2}-m^{3} e_{n}-c_{n} m^{2}+2 \gamma m e_{n}-2 m e_{n}}{2(\gamma+1)}<c_{r}<\gamma c_{n}+\gamma m e_{n}-m e_{n}$, we can obtain $q_{r}^{R *}-q_{r}^{H *}<0$. Based on Assumption 6, we get $q_{r}^{R *}<q_{r}^{H *}$.

\section{Appendix C. Proof for Proposition 3}

Since

$$
\begin{aligned}
& \pi_{M}^{H *}=\frac{\left[\begin{array}{c}
2 \gamma^{2}+8 m C \gamma^{2}-4 \gamma^{2} c_{n}-4 \gamma^{2} m e_{n}-8 m \gamma C-2 \gamma+2 \gamma m^{2} e_{n}^{2}+4 \gamma m e_{n}+4 \gamma m c_{r} e_{n}-2 c_{n}^{2} \gamma+4 \gamma c_{n} c_{r} \\
+4 \gamma c n+4 m^{3} C+m^{2} c_{n}^{2}-2 m^{3} e_{n}-2 m^{2} c_{n}-4 m e_{n} c_{r}+m^{2}+2 m^{3} e_{n} c_{n}+m^{4} e_{n}^{2}-2 c_{r}^{2}-2 m^{2} e_{n}^{2}
\end{array}\right]}{8 \gamma^{2}-8 \gamma+4 m^{2}}, \\
& {\left[2 m^{2}-8 c_{r} m e_{n}-8 \gamma+2 m^{2} c_{n}^{2}-6 \gamma^{2} m e_{n}+3 \gamma^{2}-4 m^{3} e_{n}-4 c_{n} m^{2}-6 \gamma^{2} c_{n}+16 \gamma c_{n}+16 \gamma m e_{n}\right.}
\end{aligned}
$$

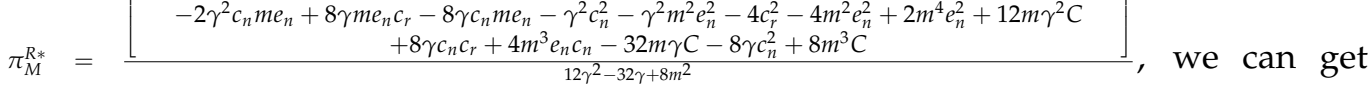

$$
\begin{aligned}
& \pi_{M}^{R *}-\pi_{M}^{H *} \quad=\quad-\frac{\gamma(\gamma+4)\left(\gamma m e_{n}+\gamma c_{n}-m e_{n}-c_{r}\right)^{2}}{2\left(3 \gamma^{2}-8 \gamma+2 m^{2}\right)\left(2 \gamma^{2}-2 \gamma+m^{2}\right)} .
\end{aligned}
$$

Since $\frac{2 \gamma^{2}-2 \gamma-4 \gamma c_{n}+m^{2}-m^{3} e_{n}-c_{n} m^{2}+2 \gamma m e_{n}-2 m e_{n}}{2(\gamma+1)}<c_{r}<\gamma c_{n}+\gamma m e_{n}-m e_{n}$, we can obtain $\pi_{M}^{R *}-\pi_{M}^{H *}<0$. Based on Assumption 6, we get $\pi_{M}^{R *}<\pi_{M}^{H *}$.

\section{Appendix D. Proof for Proposition 4}

Since

$$
\begin{aligned}
& \pi_{T}^{H *}=\pi_{M}^{H *}=\frac{\left[\begin{array}{c}
2 \gamma^{2}+8 m C \gamma^{2}-4 \gamma^{2} c_{n}-4 \gamma^{2} m e_{n} 8 m \gamma C-2 \gamma+2 \gamma m^{2} e_{n}^{2}+4 \gamma m e_{n} \\
+4 \gamma m c_{r} e_{n}-2 c_{n}^{2} \gamma+4 \gamma c_{n} c_{r}+4 \gamma c n+4 m^{3} C+m^{2} c_{n}^{2}-2 m^{3} e_{n}-2 m^{2} c_{n} \\
-4 m e_{n} c_{r}+m^{2}+2 m^{3} e_{n} c_{n}+m^{4} e_{n}^{2}-2 c_{r}^{2}-2 m^{2} e_{n}^{2}
\end{array}\right]}{8 \gamma^{2}-8 \gamma+4 m^{2}}, \\
& \pi_{T}^{T *}=\pi_{M}^{R *}+\pi_{R}^{R *} \\
& {\left[\begin{array}{c}
2 m^{2}-8 c_{r} m e_{n}-8 \gamma+2 m^{2} c_{n}^{2}-6 \gamma^{2} m e_{n}+3 \gamma^{2}-4 m^{3} e_{n}-4 c_{n} m^{2}-6 \gamma^{2} c_{n} \\
+16 \gamma c_{n}+16 \gamma m e_{n}-2 \gamma^{2} c_{n} m e_{n}+8 \gamma m e_{n} c_{r}-8 \gamma c_{n} m e_{n}-\gamma^{2} c_{n}^{2}-\gamma^{2} m^{2} e_{n}^{2}-4 c_{r}^{2} \\
-4 m^{2} e_{n}^{2}+2 m^{4} e_{n}^{2}+12 m \gamma^{2} C+8 \gamma c_{n} c_{r}+4 m^{3} e_{n} c_{n}-32 m \gamma C-8 \gamma c^{2}+8 m^{3} C
\end{array}\right]} \\
& =\frac{\left[-4 m^{2} e_{n}^{2}+2 m^{4} e_{n}^{2}+12 m \gamma^{2} C+8 \gamma c_{n} c_{r}+4 m^{3} e_{n} c\right.}{12 \gamma^{2}-32 \gamma+8 m^{2}} \\
& +\frac{4\left(\gamma c_{n}+\gamma m e_{n}-c_{r}-m e_{n}\right)^{2} \gamma}{\left(3 \gamma^{2}-8 \gamma+2 m^{2}\right)^{2}}
\end{aligned}
$$

we can get $\pi_{T}^{R *}-\pi_{T}^{H *}=-\frac{\gamma^{2}\left(3 \gamma^{2}+2 m^{2}-12 \gamma-16\right)\left(\gamma c_{n}+\gamma m e_{n}-c_{r}-m e_{n}\right)^{2}}{2\left(3 \gamma^{2}-8 \gamma+2 m^{2}\right)^{2}\left(2 \gamma^{2}-2 \gamma+m^{2}\right)}$. Since $\frac{2 \gamma^{2}-2 \gamma-4 \gamma c_{n}+m^{2}-m^{3} e_{n}-c_{n} m^{2}+2 \gamma m e_{n}-2 m e_{n}}{2(\gamma+1)}<c_{r}<\gamma c_{n}+\gamma m e_{n}-m e_{n}$, we can obtain $\pi_{T}^{R *}-\pi_{T}^{H *}<0$. Based on Assumption 6, we get $\pi_{T}^{R *}<\pi_{T}^{H *}$.

\section{Appendix E. Proof for Proposition 5}

Since $s^{H *}=\frac{m\left(\gamma m e_{n}+\gamma c_{n}-m e_{n}-c_{r}\right)}{2 \gamma-2 \gamma^{2}-m^{2}}, s^{R *}=\frac{2 m\left(m e_{n}-\gamma c_{n}-\gamma m e_{n}+c_{r}\right)}{2 m^{2}-8 \gamma+3 \gamma^{2}}$, we can get $s^{R *}-s^{H *}=-\frac{\gamma^{2}\left(3 \gamma^{2}+2 m^{2}-12 \gamma-16\right)\left(\gamma c_{n}+\gamma m e_{n}-c_{r}-m e_{n}\right)^{2}}{2\left(3 \gamma^{2}-8 \gamma+2 m^{2}\right)^{2}\left(2 \gamma^{2}-2 \gamma+m^{2}\right)}$. Since $\frac{2 \gamma^{2}-2 \gamma-4 \gamma c_{n}+m^{2}-m^{3} e_{n}-c_{n} m^{2}+2 \gamma m e_{n}-2 m e_{n}}{2(\gamma+1)}<c_{r}<\gamma c_{n}+\gamma m e_{n}-m e_{n}$, we can obtain $s^{R *}-s^{H *}<0$. Based on Assumption 6, we get $s^{R *}<s^{H *}$. 


\section{Appendix F. Proof for Proposition 6}

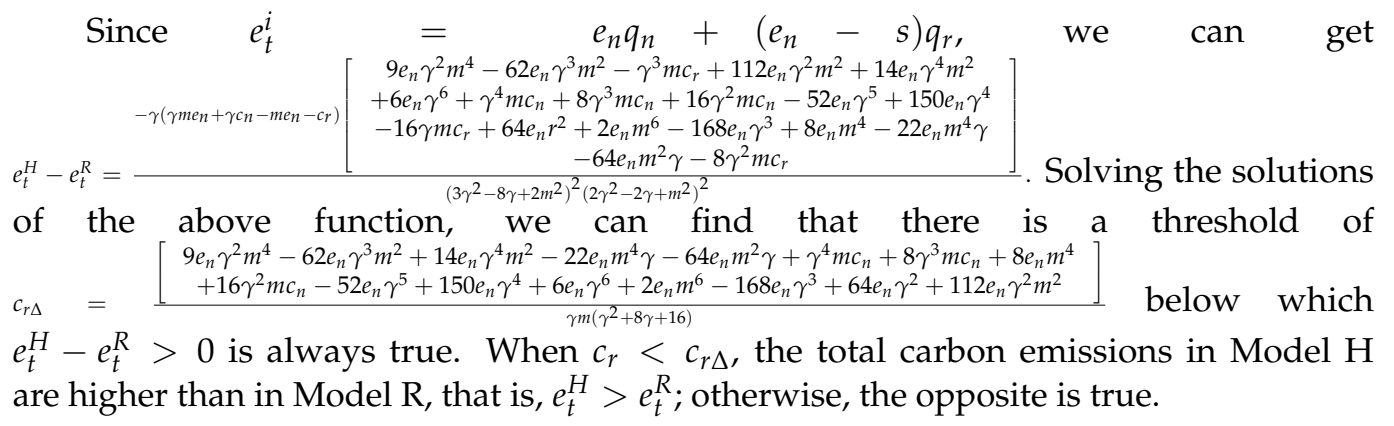

\section{References}

1. IPCC. AR5 Synthesis Report: Climate Change 2014. Core Writing Team; Pachauri, R.K., Reisinger, A., Eds.; IPCC: Geneva, Switzerland, 2014.

2. Joos, F.; Spahni, R. Rates of change in natural and anthropogenic radiative forcing over the past 20,000 years. Proc. Natl. Acad. Sci. USA 2008, 105, 1425. [CrossRef] [PubMed]

3. Dlugokencky, E.; Tans, P. Trends in Atmospheric Carbon Dioxide; National Oceanic \& Atmospheric Administration, Earth System Research Laboratory (NOAA/ESRL): Boulder, CO, USA, 2018.

4. Restuccia, A. Obama Pledges Greenhouse Gas Emissions Cuts. Politico. 31 March 2015. Available online: https://www.politico. com/story/2015/03/obama-greenhouse-gas-emissions-116544 (accessed on 13 September 2020).

5. Global Times. EU Aims to Cut Carbon Dioxide Emissions by 40 pct by 2030. Global Times. 12 January 2016. Available online: http:/ / www.globaltimes.cn/content/1021277.shtml (accessed on 18 March 2020).

6. Chai, Q.; Xiao, Z.; Lai, K.-H.; Zhou, G. Can Carbon Cap and Trade Mechanism Be Beneficial for Remanufacturing? Int. J. Prod. Econ. 2018, 203, 311-321. [CrossRef]

7. Benz, E.; Trück, S. Modeling the price dynamics of $\mathrm{CO}_{2}$ emission allowances. Energy Econ. 2009, 31, 4-15. [CrossRef]

8. Xerox. Xerox Is a World Leader in Environmental Sustainability. 2020. Available online: https://www.xerox.com/downloads/ account/usa/ZTX/EnvironmentalSustainability.pdf (accessed on 18 March 2020).

9. GREE. R\&D Strength. 2020. Available online: http://global.gree.com/ywb/aboutgree/rdstrength/index.shtml (accessed on 18 March 2020).

10. Yang, L.; Ji, J.; Wang, M.; Wang, Z. The manufacturer's joint decisions of channel selections and carbon emission reductions under the cap-and-trade regulation. J. Clean. Prod. 2018, 193, 506-523. [CrossRef]

11. Zhang, F.; Chen, H.; Xiong, Y.; Yan, W.; Liu, M. Managing collecting or remarketing channels: Different choice for cannibalisation in remanufacturing outsourcing. Int. J. Prod. Res. 2020, 58, 1-16. [CrossRef]

12. Atasu, A.; Sarvary, M.; Van Wassenhove, L.N. Remanufacturing as a Marketing Strategy. Manag. Sci. 2008, 54, 1731-1746. [CrossRef]

13. Holbein, J.R. Remanufactured Goods: An Overview of the U.S. and Global Industries, Markets, and Trade; Change in Start Time of Public Hearing. Fed. Regist. 2012, 77, 332-525.

14. Korhonen, J.; Honkasalo, A.; Seppälä, J. Circular Economy: The Concept and its Limitations. Ecol. Econ. 2018, 143, 37-46. [CrossRef]

15. Ferguson, M.E.; Souza, G.C. (Eds.) Closed-Loop Supply Chains: New Developments to Improve the Sustainability of Business Practices; CRC Press: Boca Raton, FL, USA, 2010; p. 257.

16. Hauser, W.M.; Lund, R.T. The Remanufacturing Industry: Anatomy of a Giant: A View of Remanufacturing in America Based on a Comprehensive Survey across the Industry; Dept. of Manufacturing Engineering, Boston University: Boston, MA, USA, 2003; Available online: www.bu.edu/reman (accessed on 18 October 2017).

17. Yan, W.; Li, H.; Chai, J.; Qian, Z.; Chen, H. Owning or Outsourcing? Strategic Choice on Take-Back Operations for Third-Party Remanufacturing. Sustainability 2018, 10, 151. [CrossRef]

18. Fleischmann, M.; Bloemhof-Ruwaard, J.M.; Dekker, R.; Van Der Laan, E.; Van Nunen, J.A.E.E.; Van Wassenhove, L.N. Quantitative models for reverse logistics: A review. Eur. J. Oper. Res. 1997, 103, 1-17. [CrossRef]

19. Klingelhöfer, H.E. Investments in EOP-technologies and emissions trading-Results from a linear programming approach and sensitivity analysis. Eur. J. Oper. Res. 2009, 196, 370-383. [CrossRef]

20. Du, S.; Tang, W.; Song, M. Low-carbon production with low-carbon premium in cap-and-trade regulation. J. Clean. Prod. 2016, 134, 652-662. [CrossRef]

21. Yang, L.; Chen, M.; Cai, Y.; Tsai, S.-B. Manufacturer's Decision as Consumers' Low-Carbon Preference Grows. Sustainability 2018, 2018, 1284. [CrossRef]

22. Xu, J.; Bai, Q.; Xu, L.; Hu, T. Effects of emission reduction and partial demand information on operational decisions of a newsvendor problem. J. Clean. Prod. 2018, 188, 825-839. [CrossRef]

23. Manikas, A.S.; Kroes, J.R. A newsvendor approach to compliance and production under cap and trade emissions regulation. Int. J. Prod. Econ. 2015, 159, 274-284. [CrossRef] 
24. Konur, D.; Campbell, J.F.; Monfared, S.A. Economic and environmental considerations in a stochastic inventory control model with order splitting under different delivery schedules among suppliers. Omega 2017, 71, 46-65. [CrossRef]

25. Agrawal, V.A.; Atasu, A.; Van Ittersum, K. Remanufacturing, Third-Party Competition, and Consumers' Perceived Value of New Products. Manag. Sci. 2012, 61, 60-72. [CrossRef]

26. Shi, T.; Chhajed, D.; Wan, Z.; Liu, Y. Distribution Channel Choice and Divisional Conflict in Remanufacturing Operations. Prod. Oper. Manag. 2020, 29, 1702-1719. [CrossRef]

27. $\mathrm{Wu}, \mathrm{X}$; Z Zhou, Y. Buyer-specific versus uniform pricing in a closed-loop supply chain with third-party remanufacturing. Eur. J. Oper. Res. 2019, 273, 548-560. [CrossRef]

28. Chen, C.-K.; Almakul'Ulya, M. Analyses of the reward-penalty mechanism in green closed-loop supply chains with product remanufacturing. Int. J. Prod. Econ. 2019, 210, 211-223. [CrossRef]

29. Savaskan, R.C.; Bhattacharya, S.; Van Wassenhove, L.N. Closed-Loop Supply Chain Models with Product Remanufacturing. Manag. Sci. 2004, 50, 239-252. [CrossRef]

30. Zhang, F.; Zhang, R. Trade-in Remanufacturing, Customer Purchasing Behavior, and Government Policy. Manuf. Serv. Oper. Manag. 2018, 20, 601-616. [CrossRef]

31. Giutini, R.; Gaudette, K. Remanufacturing: The next great opportunity for boosting US productivity. Bus. Horiz. 2003, 46, 41-48. [CrossRef]

32. Bai, Q.; Xu, J.; Zhang, Y. Emission reduction decision and coordination of a make-to-order supply chain with two products under cap-and-trade regulation. Comput. Ind. Eng. 2018, 119, 131-145. [CrossRef]

33. Veldman, J.; Gaalman, G.J. Competitive investments in cost reducing process improvement: The role of managerial incentives and spillover learning. Int. J. Prod. Econ. 2015, 170, 701-709. [CrossRef]

34. Miremadi, I.; Saboohi, Y. Planning for Investment in Energy Innovation: Developing an Analytical Tool to Explore the Impact of Knowledge Flow. Int. J. Energy Econ. Policy 2018, 8, 7-19.

35. Guide, V.D.R., Jr.; Li, J. The Potential for Cannibalization of New Products Sales by Remanufactured Products. Decis. Sci. 2010, 41, 547-572. [CrossRef]

36. HP. HP Innovations that Are Kind to the Environment and Your IT Budget. 2021. Available online: https://www8.hp.com/us / en/hp-information/environment/refurbished-products.html (accessed on 7 February 2021).

37. He, W.; Liang, L.; Wang, K. Economic and Environmental Implications of Quality Choice under Remanufacturing Outsourcing. Sustainability 2020, 12, 874. [CrossRef]

38. Atasu, A.; Souza, G.C. How Does Product Recovery Affect Quality Choice? Prod. Oper. Manag. 2011, 22, 991-1010. [CrossRef]

39. Esenduran, G.; Kemahlığlu-Ziya, E.; Swaminathan, J.M. Take-Back Legislation: Consequences for Remanufacturing and Environment. Decis. Sci. 2016, 47, 219-256. [CrossRef]

40. Swami, S.; Shah, J. Channel coordination in green supply chain management. J. Oper. Res. Soc. 2013, 64, 336-351. [CrossRef] 